\title{
Seasonal changes in photosynthesis, phenolic content, antioxidant activity, and anatomy of apical and basal leaves of Aristotelia chilensis
}

\author{
K. CRISÓSTOMO-AYALA ${ }^{1, *}\left(\mathbb{D}\right.$, M. HERNÁNDEZ DE LA TORRE $^{1} \mathbb{D}$, M.A. PEDREÑO ${ }^{2}$ (D), \\ J.A. HERNÁNDEZ ${ }^{4}$ (D), C. PÉREZ ${ }^{3}$ (D), E. BUSTOS ${ }^{3}$ iD, M. SÁNCHEZ-OLATE ${ }^{1}$ (D) and D. RÍOS ${ }^{1, *}$ (iD \\ ${ }^{1}$ Centro de Biotecnología, Facultad de Ciencias Forestales, Universidad de Concepción, Concepción, 4070386, \\ Chile \\ ${ }^{2}$ Departamento de Biología Vegetal, Facultad de Biología, Universidad de Murcia, Murcia, E-30100, España \\ ${ }^{3}$ Departamento de Botánica, Facultad de Ciencias Naturales y Oceanográficas, Universidad de Concepción, \\ 4070386, Concepción, Chile \\ ${ }^{4}$ Grupo de Biotecnología de Frutales, Departamento de Mejora Genética, CEBAS-CSIC, Murcia, E-30100, España
}

*Corresponding authors: E-mails: karicrisostomo@udec.cl; drios@udec.cl

\begin{abstract}
Aristotelia chilensis (Mol.) Stuntz is an evergreen species endemic to Chile. It grows in open areas or under tree canopy, and its leaves emerge in early spring and summer. The objective of this study was to determine changes in photosynthetic parameters, total phenol content (TPC), antioxidant activity, and anatomy of apical and basal leaves of A. chilensis during the year. Photosynthesis performance was determined by measuring electron transport rate (ETR), the quantum efficiency of photosystem II $\left(\mathrm{F}_{\mathrm{v}} / \mathrm{F}_{\mathrm{m}}\right)$, photochemical quenching $(\mathrm{qP})$, and non-photochemical quenching (NPQ) with a fluorimeter. Leaf extracts were analysed to determine TPC and antioxidant activity. The maximum ETR and $\mathrm{qP}$ were recorded in spring and summer when the photosynthetically active radiation (PAR) at midday was higher (1901 and $1968 \mu \mathrm{mol} \mathrm{m} \mathrm{m}^{-2} \mathrm{~s}^{-1}$, respectively) than in other parts of a year. The $\mathrm{F}_{\mathrm{v}} / \mathrm{F}_{\mathrm{m}}$ had typical physiological values in both types of leaves (about 0.8 in all the seasons). Also the NPQ was not influenced by the kind of leaves and season of the year. In concordance, the basal spring leaves had the highest TPC values. In contrast, the highest values of antioxidant activity were recorded in basal winter leaves followed by basal spring leaves. The results suggested that an increase in PAR (spring) positively affected the antioxidant activity and TPC, which correlated with higher ETR and qP values. The apical leaves showed morphological adaptations during the year and areas of intercellular spaces and palisade parenchyma were larger than in the basal leaves.
\end{abstract}

Keywords: antioxidants, Aristotelia chilensis, chlorophyll fluorescence, leaf anatomy, phenolic compounds.

Received 4 May 2021, last revision 28 June 2021, accepted 25 August 2021.

Abbreviations: ABTS - 2,2'-azino-bis 3-ethylbenzothiazoline-6-sulfonate; DPPH - 1,1-diphenyl-2-picrylhydrazyl; ETR - electron transport rate; $F_{0}$ - minimum fluorescence; $F_{m}$ - maximum fluorescence; $F_{v}$ - variable fluorescence; $F_{v} / F_{m}$ - maximal photochemical efficiency of PS II; NPQ - non-photochemical quenching; PAR - photosynthetically active radiation; PS II - photosystem II; qP - photochemical quenching; ROS - reactive oxygen species; TPC - total phenol content; ФPSII - efficiency of photosystem II. Acknowledgements: This research was supported by the VRID project 218.142.037-1.0 "Evaluation of phenolic and alkaloids compounds production from vegetative organs of Aristotelia chilensis: an effective alternative for sustainable use"; Universidad de Concepción, Chile. The authors are grateful for the support provided by Instituto de Ciências Biológicas, Universidade Federal de Minas Gerais, Belo Horizonte, Minas Gerais, Brasil. Beca ANID Doctorado Nacional 2019/21191038 is greatly acknowledged.

Conflict of interest: The authors declare that they have no conflict of interest. 


\section{Introduction}

Many plant species, including trees, grow under adverse environmental conditions. Aristotelia chilensis (Mol.) Stuntz is a dioic evergreen tree which is commonly known as "maqui" and native to Chile. This plant develops preferably in humid and drained soils of the central valley, in the slopes of both mountain ranges, streams, and margins of forests, from near sea level to $2500 \mathrm{~m}$ altitude (Zúñiga et al. 2017). A. chilensis grows up to $4-5 \mathrm{~m}$, it has a soft and smooth bark, and abundant, thin and flexible ramifications. Leaves are simple, oval-lanceolate with dentate edges and range from 4 to $9 \mathrm{~cm}$ in size. The leaves veins are marked with a long reddish petiole and stems are characterized by an intense red colour. Flowering occurs in the beginning of spring and the fruits are harvested once a year from December to February (Turchetti and Paz 2019). In addition, A. chilensis plants tolerate drought periods of less than one month. This species appears in succession as a colonizer of newly burned or exploited soils, forming dense and monospecific groups known as "macales" with the function of reducing erosion and generating the conditions for establishing other species forming secondary shrubs (Salinas and Caballé 2020).

Variations in environmental factors such as temperature, irradiance, water availability, among others, can cause stress and therefore, changes in plant metabolism. In fact, the photosynthetic rate decreases due to an alteration in the electron transport mechanism and $\mathrm{CO}_{2}$ assimilation, which is finally reflected in a decrease in sugar production (Mathur et al. 2018). Plants, in their interaction with the environment, produce a high number of secondary metabolites, which are normally not essential for their primary metabolism. The synthesis of these compounds is enhanced under stress conditions and many of them have biological activities which are beneficial to human health, and are used as biologically active compounds (Scossa and Fernie 2020). The phenolic compounds are useful in the prevention of arteriosclerosis, cancer, diabetes, neurodegenerative diseases and arthritis (Gonçalves and Romano 2017).

A. chilensis fruits have been studied intensively (Masoodi et al. 2019) and they are used for pharmacological (Céspedes et al. 2017, Ortiz et al. 2021) and nutraceuticals purposes (Fredes et al. 2018, Agulló et al. 2021). Their fruits are bright black edible berries, with a high content of anthocyanin, thus, they have up to four times more antioxidants properties than other berries (Fredes et al. 2014, 2018, Fuentes et al. 2019). However, the national and international demand for these fruits is growing and thus, affects its genetic heritage and biodiversity. Faced with the drawbacks of the unregulated collection of fruits, the proposal to use leaves as a source of phenolic compounds arises, constituting an alternative that can be sustainable, permanent, and that does not affect the state of conservation of the species.

A. chilensis leaves emerge along the branch in two periods of the year, one more abundant in early spring, and another, in summer. As evergreen species, A. chilensis plants retain their leaves during winter and they remain photosynthetically active, both in the days of moderate temperature in autumn and winter, and during the early spring (Moya et al. 2019). However, there are limited studies on the behaviour of phenolic compounds in leaves in relation to their morpho-phenological and physiological development in a seasonal period.

The present work relates the age of the leaves of A. chilensis to the photosynthetic capacity and accumulation of phenolic compounds as well as their antioxidant capacity under different natural growth conditions.

\section{Materials and methods}

This research was conducted between August 2017 and January 2018, the period in which the leaves of Aristotelia chilensis (Mol.) Stuntz were collected, at the Universidad de Concepción, Biobío Region, Chile $\left(36^{\circ} 50^{\prime} 02.6\right.$ "S, $\left.73^{\circ} 01^{\prime} 54.3^{\prime \prime} \mathrm{W}\right)$. The influence of climatic conditions on annual seasons in which this study was carried out is shown in Table 1 Suppl. (data from Dirección Meteorológica de Chile 2018). In addition, the photosynthetically active radiation (PAR) measurements obtained at midday in the study seasons are presented in Table 1 Suppl.

Adult male $A$. chilensis plants growing in a natural environment and reaching a uniform height of $3 \mathrm{~m}$ were used. Six plants were selected within the university campus. According to González-Villagra et al. (2018) two different positions represented different ages: young leaves, from the upper third of the branch (apical leaves), and fully expanded leaves, from the lower third of the branch corresponding to basal leaves. The study was carried out with fully expanded leaves, where adult and young leaves were distinguished.

Chlorophyll fluorescence: The branch obtained from the complete plant was put in the dark for $30 \mathrm{~min}$ and then exposed to different irradiances of 12.13, $25.62,51.39,86.64,241.50,479.08,878.08$, and $1280.83 \mu \mathrm{mol}$ (photons) $\mathrm{m}^{-2} \mathrm{~s}^{-1}$. Fluorescent signals were measured with a pulse amplitude fluorimeter (FMS 2, Hansatech Instrument, King's Lynn, UK). Following the terminology of Murchie and Lawson (2013), the minimum value for chlorophyll fluorescence $\left(\mathrm{F}_{0}\right)$ in the darkadapted state was determined by applying a weak pulse of modulated radiation, and the maximum fluorescence $\left(F_{m}\right)$ was induced by a short pulse $(0.8 \mathrm{~s})$ of saturating radiation. The fluorescence signals were followed until they reached a steady state $\left(\mathrm{F}_{\mathrm{s}}\right)$. To determine the maximal fluorescence under irradiance $\left(\mathrm{F}_{\mathrm{m}}{ }^{\prime}\right)$, various pulses of saturating radiation were applied. The minimal value for chlorophyll fluorescence $\left(\mathrm{F}_{0}{ }^{\prime}\right)$ in the radiation-adapted state was determined by turning off the actinic radiation, and immediately applying a $2 \mathrm{~s}$ far-red pulse.

The maximum photochemical efficiency of photosystem II (ФPSII), $\mathrm{F}_{\mathrm{v}} / \mathrm{F}_{\mathrm{m}}$ (variable fluorescence/ maximal fluorescence) was calculated considering $\mathrm{F}_{\mathrm{v}}=\mathrm{F}_{\mathrm{m}}-\mathrm{F}_{0}$. Once data from fluorimeter were obtained, the efficiency of photosystem II $\left(\right.$ ФPSII $\left.=\left(\mathrm{F}_{\mathrm{m}}{ }^{\prime}-\mathrm{F}_{\mathrm{s}}\right) / \mathrm{F}_{\mathrm{m}}{ }^{\prime}\right)$, and the electron transport rate 
$(\mathrm{ETR}=0.8 \times \Phi$ PSII $\times$ PAR $\times 0.5)$ were calculated The constants of equation are factor 0.8 in which the average value of the absorbance for the green leaves, and the factor 0.5 assumes that the efficiency of both photosystems is equal, and that the radiation is distributed equally among them (Yang et al. 2020). In addition, photochemical quenching $\left(\mathrm{qP}=\left(\mathrm{F}_{\mathrm{m}}{ }^{\prime}-\mathrm{F}_{\mathrm{s}}\right) /\left(\mathrm{F}_{\mathrm{m}}-\mathrm{F}_{\mathrm{o}}{ }^{\prime}\right)\right)$ and non-photochemical quenching $\left(\mathrm{NPQ}=\left(\mathrm{F}_{\mathrm{m}}-\mathrm{F}_{\mathrm{m}}{ }^{\prime}\right) / \mathrm{F}_{\mathrm{m}}{ }^{\prime}\right)$ were calculated (Yang et al. 2020).

In the different seasons of the year (winter, spring, and summer), branches of $A$. chilensis were collected, and apical and basal leaves were identified. The samples were collected at midday where the radiation is highest. At this time, the photosynthetically active radiation (PAR) was measured, and the radiation condition of the environment of the studied plants was established based on the criteria described by Zhen and Bugbee (2020). The PAR data are shown in Table 1.

Preparation of $\boldsymbol{A}$. chilensis samples for anatomical studies: The tissue was selected from the central portion of the both types of leaves from the three seasons of the year, cut quickly and fixed in $3.7 \%(\mathrm{v} / \mathrm{v})$ formaldehyde, $70 \%$ ethanol $(\mathrm{v} / \mathrm{v})$ and $5 \%$ acetic acid, $\left(\mathrm{FAA}_{70}\right)$. The samples were dehydrated through serial solutions in ethanol and $n$-butyl acetate, and embedded in paraplast. The cuts were made with a Jung Biocut 2035 microtome and stuck in glass sheets with Hatsup and Bissmut adhesives. After removing the paraplast by dipping in butyl acetate and washing with ethanol, the samples were coloured with safranin and Astra blue. Subsequently, they were re-dehydrated in a series of dilutions of ethanol and finally in butyl acetate. Glass sheets were visualized in a Leica ICC50 HP (Leica Microsystems (Schweiz) AG, Heerbrugg, Switzerland). optical microscope according to nomenclature proposed by Dos Santos Isaias et al. (2011). The measurement of morphological characteristics was done using AxioVision SE64 Rel. 4.9.1 software (Zeiss, Jena, Germany) with contrasting the scale to determine the area of adaxial epidermis, palisade parenchyma, spongy parenchyma, abaxial epidermis, and intercellular space.

Determination of total phenolic content (TPC): Fresh basal and apical leaves ( $40 \mathrm{~g})$ were dried at $37^{\circ} \mathrm{C}$ for two days. Dried leaves were crushed to obtain powder and then, maceration was performed by exhaustion in $0.1 \%$ methanol-HCl. The total extract was concentrated in a rotavapor at $37^{\circ} \mathrm{C}$ and lyophilized for $24 \mathrm{~h}$. The extraction yield was defined as the amount of extract recovered by leaf dry mass for each sample.

The total phenolic content (TPC) in each extract/sample was determined using method described by Sembiring et al. (2018) with slight modifications. The dried sample was dissolved in distilled water to a concentration of $200 \mu \mathrm{g} \mathrm{cm}^{-3}$. The calibration curve was established using gallic acid (10 to $200 \mu \mathrm{g} \mathrm{cm}^{-3}$ ). The reaction mixture contained: distilled water $\left(400 \mathrm{~mm}^{3}\right)$, sample or gallic acid solution for the standard curve $\left(20 \mathrm{~mm}^{3}\right)$, Folin-Ciocalteu reagent $\left(40 \mathrm{~mm}^{3}\right)$ and $15 \%(\mathrm{~m} / \mathrm{v})$ sodium carbonate $\left(200 \mathrm{~mm}^{3}\right)$. The reaction mixture was incubated at room temperature for $60 \mathrm{~min}$ in darkness, with intermittent shaking to aid colour development. Absorbance was measured at $750 \mathrm{~nm}$ using UV-Vis spectrophotometer (BioTeK ELx800, Winooski, Vermont, USA). TPC was expressed in mg of gallic acid equivalents (GAE) per gram of dry mass.

DPPH radical scavenging assay: The free radical scavenging activity of $A$. chilensis leaf extracts and standard solution Trolox ( \pm-6 -hydroxy-2,5,7,8tetramethylchromane-2-carboxylic acid) were analysed using 1,1-diphenyl-2-picrylhydrazyl (DPPH) radical scavenging method as reported by Masek et al. (2020). The assay mixture contained $270 \mathrm{~mm}^{3}$ of $0.06 \mathrm{mM} \mathrm{DPPH}$ radical solution, prepared in methanol, and $30 \mathrm{~mm}^{3}$ of Trolox in different concentrations (10 to $200 \mu \mathrm{g} \mathrm{cm}^{-3}$ ) or $A$. chilensis leaf extracts. The reaction mixtures were quickly mixed and incubated in darkness at $37{ }^{\circ} \mathrm{C}$ for $20 \mathrm{~min}$. The decrease in absorbance of each sample was measured at $515 \mathrm{~nm}$ using UV/Vis spectrophotometer. Trolox, a well-known antioxidant, was used as positive control, while DPPH radical solution with $1 \mathrm{~cm}^{3}$ methanol was taken as blank. All determinations were performed in triplicate.

ABTS radical scavenging assay: For ABTS assay, the procedure described by Masek et al. (2020) was followed with some modifications. The stock solutions included $3.5 \mathrm{mM}$ ABTS (2,2'-azino-bis 3-ethylbenzothiazoline-6sulfonate) and $1.22 \mathrm{mM}$ potassium persulfate. The working solution was then prepared by mixing the two stock solutions in equal quantities and allowing them to react for $16 \mathrm{~h}$ at room temperature in darkness. After the $\mathrm{ABTS}^{*+}$ radical was formed, the solution was then diluted by mixing $1 \mathrm{~cm}^{3}$ of $\mathrm{ABTS}^{*+}$ solution with $14 \mathrm{~cm}^{3}$ of distilled water to obtain an absorbance value of $0.70 \pm 0.01$ units at $750 \mathrm{~nm}$. ABTS $^{*+}$ solution was freshly prepared for each assay. The reaction $\left(60 \mathrm{~min}\right.$, in dark conditions) contained $\mathrm{ABTS}^{*+}$ radical $\left(180 \mathrm{~mm}^{3}\right)$ and $20 \mathrm{~mm}^{3}$ of the samples at different concentrations. For standard Trolox and samples, dilutions of 10 to $200 \mu \mathrm{g} \mathrm{cm}^{-3}$ were prepared. All determinations were performed in triplicate. The antioxidant activity was expressed as percentage of inhibition, which corresponds to the amount of radical (DPPH and ABTS) neutralized by the extract at a certain concentration, as described in the following equation: inhibition $[\%]=\left[\left(\mathrm{A}_{\mathrm{c}}-\mathrm{A}_{\mathrm{s}}\right) / \mathrm{A}_{\mathrm{c}}\right]$ $\times 100$, where, $A_{c}$ is the absorbance of the control and $A_{s}$ the absorbance of the samples. The antioxidant activity was expressed as $\mathrm{IC}_{50}$, which was defined as the final concentration $\left(\mu \mathrm{g}\right.$ extract $\mathrm{cm}^{-3}$ ) of the tested sample required for the inhibition of radical by $50 \%$ (Rubilar et al. 2011, De Menezes et al. 2021).

Statistical Analysis: For the radiation response curves, eight samples from six plants were used for both apical and basal type of leaf in relation to the season of the year studied. For the determination of TPC, six plant samples were used for each type of leaf in relation to the season of the year studied. For the foliar anatomy measurements, five samples with fifteen repetitions were used. The analyses were carried out with the AxioVision LE 4.8.2.0 software 
(Carl Zeiss MicroImaging GmbH, Oberkochen, Germany). The assays for the determination of antioxidant activity were carried out in triplicate. The data obtained were analysed statistically using analysis of variance (ANOVA), and the differences between the means were determined through the Tukey test $(P \leq 0.05)$. Statistical analyses were performed using the InfoStat/L software (FCAUNC, Córdoba, Argentina) and the graphic representations were made using SigmaPlot software version 10.0 (SPSS, Chicago, IL, USA).

\section{Results}

The chlorophyll fluorescence data of $A$. chilensis were affected by seasons of the year, especially ETR (Table 1). On the other hand, quantum efficiency of the PS II $\left(\mathrm{F}_{\mathrm{v}} / \mathrm{F}_{\mathrm{m}}\right)$ was only slightly affected by the leaf type but not by the environmental conditions or their interactions. However, qP and NPQ were significantly affected by the leaf type and the season, and an interaction between both variables (season and leaf type) was observed (Table 2 Suppl.).

Radiation response curves showed that the maximum values of ETR were obtained in the seasons of the year with higher radiation (spring and summer) in both types of leaves (basal and apical) as shown in Table 1. In fact, the minimum values were observed in winter, regardless of the type of leaf, showing a strong correlation of ETR with PAR during this season The values of $\mathrm{F}_{\mathrm{v}} / \mathrm{F}_{\mathrm{m}}$, remained about 0.80 in all the seasons of the year, without significant differences among them. In the same way, $F_{v} / F_{m}$ values showed no significant differences between basal and apical leaves (Table 1 and Table 2 Suppl.).

The photochemical quenching $(\mathrm{qP})$ is the ratio of excitation energy trapped by open reaction centres that has been used for electron transport (Yang et al. 2020). It was observed that the highest $\mathrm{qP}$ values were recorded in spring and summer, in both types of leaves, and they all showed significant differences with respect to the data obtained during the winter (Table 1). However, there were no significant differences in $\mathrm{qP}$ values in apical and basal leaves during winter, when the lowest values of $\mathrm{qP}$ were obtained.

The non-photochemical quenching (NPQ) indicates the influence of non-photochemical processes on the fluorescence emission from chlorophyll (Yang et al. 2020). The type of leaf used and the seasons of the year did not influence the NPQ, although a trend of increase of NPQ values especially in apical leaves correlated with the increase of radiation during spring and summer, (Table 1 and Table 2 Suppl.).

Fig. 1 shows cross sections of basal and apical fully expanded leaves. Important anatomical differences were observed mainly in the distribution of palisade and spongy parenchyma of both types of leaves. In apical leaves (Fig.1B), the area of palisade parenchyma was larger than in the basal leaves. Also, the basal leaves had smaller intercellular spaces than the apical leaves. However, no significant changes were recorded in the epidermis in both types of leaves (Table 2).
Fig. 1 Suppl. shows the yield of the extract prepared during process of determination of phenolics, which was obtained from basal and apical leaves of $A$. chilensis, in the different seasons of the year. The yields from both apical and basal leaves in winter were lower than in spring and summer.

Total phenolics content (TPC) was significantly different in basal and apical leaves, and in different seasons (Fig. 2). The highest values were recorded in extract obtained from basal leaves in spring, followed by apical leaves in winter and summer. The lowest TPC was recorded in basal leaves in winter and in apical leaves in spring. The interaction between season and leaf type was observed (Table 3 Suppl.).

According to $F$-values from two-way $A N O V A$, the antioxidant activities obtained by both methodologies (ABTS and DPPH), were influenced by the season of the year, the type of leaf, and the interaction between both factors (Table 3 Suppl). In addition, the antioxidant activity for ABTS assay expressed as a function of $\mathrm{IC}_{50}$ is shown in Table 3. Data described in this table show significant differences between apical and basal leaves as well as during seasons. The most antioxidant activity values are represented by the smallest amount of sample necessary to inhibit an oxidizing agent. The best result of this ABTS antioxidant activity was found in basal winter leaves, which corresponds to the lower value of $\mathrm{IC}_{50}$, followed spring and summer basal leaves.

The $\mathrm{IC}_{50}$ values obtained from DPPH assay (Table 3) were significantly different during seasons in both types of leaves as confirmed by their $F$ values. Although, the differences in antioxidant activity were small, basal leaves during winter had a higher antioxidant activity than in spring and summer. Regarding apical leaves, the antioxidant activity was lower in summer than in winter and spring.

\section{Discussion}

Weather conditions characterize the different seasons of the year. They affect both the morphology and physiology of the plant, and therefore, they modify the growth and development of its organs, including the leaves. The objective of this work was to analyse the effect of seasons on $A$. chilensis leaves. As maqui leaves emerge in two periods of the year, one more abundant in spring, and another, in summer. These two seasons were selected to carry out this study. In addition, a third season, winter, was also selected because $A$. chilensis plants retain their leaves during this period and they remain photosynthetically active. In general, the winter leaves have different morphological and physiological characteristics. Also, apical leaves continuously grow and act as consumptive sinks while basal leaves, being adult leaves, are sources of photosynthetic products.

In fact, Damascos and Prado (2001b) indicated that adult leaves of A. chilensis in winter, remained photosynthetically active during the spring and until 15 days before the senescence. These leaves showed higher average values of 
Table 1. Effect of the season of the year on fluorescence parameters in basal and apical leaves of $A$. chilensis. Means \pm SEs from eight samples of each season of the year. Different letters in the same row indicate significant differences according to Tukey's test $(P \leq 0.05)$. $F$ values from ANOVA for the different season of the year and type of leaf. *, ** - significant at 95 and $99 \%$ level of probability, respectively, ns - non-significant.

\begin{tabular}{llcrcc}
\hline Leaves & Parameters & \multicolumn{1}{l}{ Winter } & \multicolumn{1}{c}{ Spring } & Summer & $F$ \\
\hline Basal leaf & ETR & $64.02 \pm 6.47 \mathrm{a}$ & $129.71 \pm 13.69 \mathrm{~b}$ & $108.83 \pm 4.83 \mathrm{~b}$ & $13.38^{* *}$ \\
& $\mathrm{qP}$ & $0.25 \pm 0.03 \mathrm{~b}$ & $0.47 \pm 0.04 \mathrm{a}$ & $0.42 \pm 0.02 \mathrm{a}$ & $13.81^{* *}$ \\
& $\mathrm{~F}_{\mathrm{v}} / \mathrm{F}_{\mathrm{m}}$ & $0.83 \pm 0.01 \mathrm{a}$ & $0.84 \pm 0.005 \mathrm{a}$ & $0.84 \pm 0.01 \mathrm{a}$ & $0.97 \mathrm{~ns}$ \\
Apical leaf & $\mathrm{NPQ}$ & $3.42 \pm 0.11 \mathrm{a}$ & $3.79 \pm 0.15 \mathrm{a}$ & $3.84 \pm 0.22 \mathrm{a}$ & $1.85 \mathrm{~ns}$ \\
& $\mathrm{ETR}$ & $85.75 \pm 5.25 \mathrm{a}$ & $123.08 \pm 12.58 \mathrm{~b}$ & $122.19 \pm 3.64 \mathrm{~b}$ & $6.84^{*}$ \\
& $\mathrm{qP}$ & $0.35 \pm 0.02 \mathrm{~b}$ & $0.48 \pm 0.04 \mathrm{a}$ & $0.51 \pm 0.01 \mathrm{a}$ & $13.35^{* *}$ \\
& $\mathrm{~F}_{\mathrm{v}} / \mathrm{F}_{\mathrm{m}}$ & $0.83 \pm 0.004 \mathrm{a}$ & $0.82 \pm 0.01 \mathrm{a}$ & $0.82 \pm 0.004 \mathrm{a}$ & $1.16 \mathrm{~ns}$ \\
& $\mathrm{NPQ}$ & $3.85 \pm 0.14 \mathrm{a}$ & $3.89 \pm 0.14 \mathrm{a}$ & $4.27 \pm 0.07 \mathrm{a}$ & $3.44 \mathrm{~ns}$ \\
\hline
\end{tabular}

Table 2. Measurements of areas $\left[\mu \mathrm{m}^{2}\right]$ in cross sections of basal and apical leaves of $A$. chilensis. Means \pm SEs of 75 measurements sampled in spring. Different letters in the same row indicate significant differences according to Tukey's test $(P \leq 0.05)$. $F$ values from one-way ANOVA for the different types of leaf. ** - significant at $99 \%$ level of probability, ns - non-significant.

\begin{tabular}{llcr}
\hline & Basal leaf & Apical leaf & $F$ \\
\hline Adaxial epidermis & $243.27 \pm 8.24 \mathrm{a}$ & $257.25 \pm 7.51 \mathrm{a}$ & $1.57 \mathrm{~ns}$ \\
Palisade parenchyma & $266.78 \pm 7.16 \mathrm{a}$ & $336.98 \pm 5.33 \mathrm{~b}$ & $61.81^{* *}$ \\
Spongy parenchyma & $203.50 \pm 7.97 \mathrm{a}$ & $214.33 \pm 4.91 \mathrm{a}$ & $2.52 \mathrm{~ns}$ \\
Abaxial epidermis & $135.29 \pm 5.28 \mathrm{a}$ & $140.85 \pm 3.38 \mathrm{a}$ & $0.79 \mathrm{~ns}$ \\
Intercellular space & $888.71 \pm 23.26 \mathrm{a}$ & $1165.04 \pm 31.42 \mathrm{~b}$ & $49.97^{* *}$ \\
\hline
\end{tabular}

Table 3. Antioxidant activity (determined by ABTS and DPPH assays) expressed as a function of the $\mathrm{IC}_{50}$ obtained for each type of leaf and season of the year. Means \pm SEs of three samples from each season of the year. Different letters in the same row indicate significant differences according to Tukey's test $(P \leq 0.05) . F$ values from one-way ANOVA for the different types of leaves. ${ }^{*}, * *$ - significant at 95 and $99.9 \%$ level of probability, respectively.

\begin{tabular}{lllllc}
\hline Leaves & Parameters & Winter & Spring & Summer & $F$ \\
\hline Basal leaf & ABTS & $45.05 \pm 0.30 \mathrm{a}$ & $49.97 \pm 2.24 \mathrm{~b}$ & $49.91 \pm 0.97 \mathrm{~b}$ & $11.88^{*}$ \\
& DPPH & $34.68 \pm 0.58 \mathrm{a}$ & $35.92 \pm 0.90 \mathrm{ab}$ & $38.08 \pm 1.65 \mathrm{~b}$ & $6.93^{*}$ \\
Apical leaf & ABTS & $51.81 \pm 4.59 \mathrm{a}$ & $69.02 \pm 4.21 \mathrm{~b}$ & $56.05 \pm 4.21 \mathrm{a}$ & $12.81^{*}$ \\
& DPPH & $59.49 \pm 1.87 \mathrm{c}$ & $47.37 \pm 0.63 \mathrm{~b}$ & $33.89 \pm 1.53 \mathrm{a}$ & $236.03^{* * *}$ \\
\hline
\end{tabular}

photosynthesis and expressed a best efficient use of water than the new leaves, incluid when was subjected to a low photonic flow density $\left(150 \mathrm{mmol} \mathrm{m}^{-2} \mathrm{~s}^{-1}\right)$. These authors indicated that the new leaves in the spring constitute sinks of mass and energy. However, the formation and growth of the reproductive structures of the plant are processes with high energy demand. In other studies conducted on evergreen species, it was found that the conservation of leaves from winter to spring was not associated with the translocation of nutrients before the formation of new leaves but to maintain a positive carbon balance in less favourable periods (Mendoza et al. 2014).

Murchie and Lawson (2013) carried out a review on how fluorescence parameters can be used to evaluate changes in photosystem II photochemistry, linear electron flux, and $\mathrm{CO}_{2}$ assimilation in vivo, and described the theoretical bases for the use of specific fluorescence parameters. In relation to these parameters, apical leaves showed lower $F_{v} / F_{m}$ values trend than basal leaves during spring and summer, although, the data obtained were constantly within the normal physiological values (about 0.8) throughout the year, indicating no environmental stress (Table 1). This agrees with the results of the current study (Table 1) and thus, the $\mathrm{F}_{\mathrm{v}} / \mathrm{F}_{\mathrm{m}}$ confirmed that a photoinhibition of the photosynthetic apparatus did not occur. This could be due to two reasons: either $A$. chilensis is tolerant to high radiation (Moya et al. 2019), or it was not under another stress, making it to achieve the optimum physiological performance in any season of the year (Molina-Montenegro et al. 2012). Other studies confirmed that this species has a great phenotypic plasticity in traits associated with carbon gain and water economy, which improves survival both under habitats with low radiation and water availability (continuous forest), and with high radiation conditions and water scarcity (Moya et al. 2019).

In the present study, ETR and $\mathrm{qP}$ values were wellcorrelated and appeared to be dependent on leaf irradiance. In A. chilensis basal leaves, both ETR and $\mathrm{qP}$ values were slightly higher in spring and summer than in winter. AcostaMotos et al. (2015a) studied the effect of high irradiance 
on chlorophyll fluorescence parameters in apical and basal leaves of myrtle plants. Under high irradiance, basal leaves of myrtle plants showed higher values for $\mathrm{qP}, \mathrm{F}_{\mathrm{v}} / \mathrm{F}_{\mathrm{m}}$, and NPQ than apical leaves (Acosta-Motos et al. 2015a). These results partially agree with those of the present study, because $\mathrm{F}_{\mathrm{v}} / \mathrm{F}_{\mathrm{m}}$ values of $A$. chilensis leaves were influenced by leaf type, with stable $\mathrm{F}_{\mathrm{v}} / \mathrm{F}_{\mathrm{m}}$ values in basal leaves and apical leaves under high irradiance (spring and summer). This result can be due to a down-regulation mechanism of PS II in high irradiance of apical leaves, which were more exposed to sunlight than basal leaves. A similar response in $F_{v} / F_{m}$ values has been observed in pea leaves subjected to high irradiance (Hernández et al. 2004). On the other hand, higher NPQ means that much of the energy of absorbed radiation is dissipated by the protective mechanisms. However, in the results of the current study, NPQ was different among the apical and basal leaves, but no significant change was recorded for NPQ values during different seasons. In contrast, in basal myrtle leaves, high NPQ values were observed during periods of high radiation, which could facilitate the safe removal of excess radiation energy and minimize the generation of ROS (Acosta-Motos et al. 2015a).

Variations in leaf size within each plant species depend generally on the chronological and physiological age of the developing plant and their architectural model. The architectural model is an inherent growth strategy that defines the manner in which the plant expands its form in response to morphological features (Barthélémy and Caraglio 2007). In A. chilensis, basal leaves are the largest and young leaves (apical leaves) are smaller. Furthermore, in this study, some differences in foliar anatomy were found between apical and basal leaves. These differences can be reflected in $\mathrm{F}_{\mathrm{v}} / \mathrm{F}_{\mathrm{m}}$ values, which were higher in basal leaves during spring and summer. Higher photosynthetic activity could be explained by the fact that the basal leaves are older leaves and are also the source of carbon (Damascos and Prado 2001b).

Interestingly, apical leaves had a higher percentage of area occupied by palisade parenchyma, an adaption that could favour the photosynthetic process. Nevertheless, these results indicated that the photosynthetic activity of

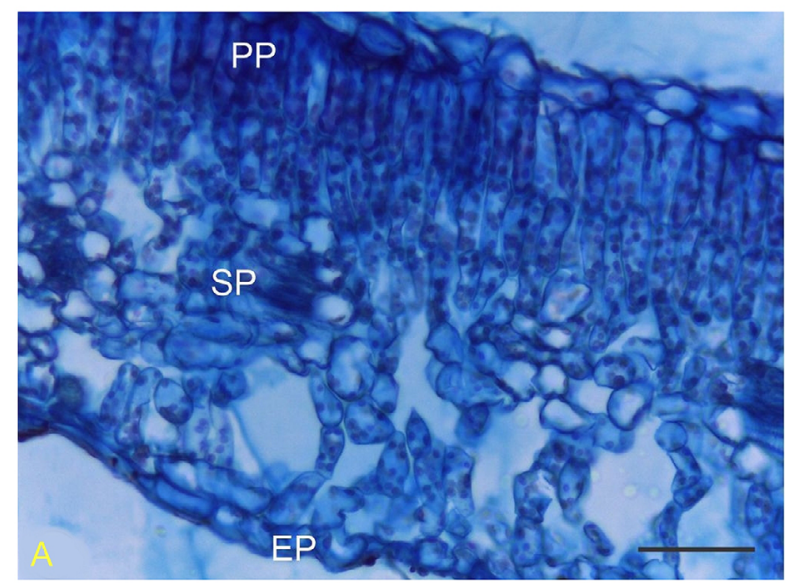

Fig. 1. Cross section of basal $(A)$ and apical $(B)$ leaves of A. chilensis. Black bars: $50 \mu \mathrm{m}$. EP - epidermis, PP - palisade parenchyma, SP - spongy parenchyma. apical leaves was lower than of basal leaves.

Another interesting difference was the greater intercellular spaces observed in the apical leaves in relation to basal leaves. This anatomical modification in leaves into the chloroplast, especially under stress conditions. A similar modification was previously described in et al. 2015a,b). These authors observed a decrease in the percentage of spongy parenchyma, and an increased percentage of intercellular spaces under $\mathrm{NaCl}$-stress. They concluded that these anatomical changes may serve to facilitate $\mathrm{CO}_{2}$ diffusion in a situation of reduced stomatal aperture (Acosta-Motos et al. 2015a,b). However, in contrast to this study, the apical leaves of $A$. chilensis were not under stress condition. The evidence suggests that an increase of parenchyma palisade and intercellular spaces of the apical leaves is an adaptation to environmental conditions.

A. chilensis berries are characterized by higher content of phenolics as compared to other berries, and the nutritional and pharmacological effects are attributed to them. The TPC observed in this study were lower than those reported by Vidal et al. (2013) and by Rubilar et al. (2011) for A. chilensis leaves collected in Región del Biobío probably due to a different extraction procedure. The plants are constantly exposed to multifactorial environmental changes that are unfavourable for growth and development. However, phenolic compounds like flavonoids play a significant role in UV protection. Several studies confirmed that excess light or UV radiation changes the flavonoids composition of plant leaves in response to photodestruction and photoprotection (Naikoo et al. 2019). In addition, phenolic compounds exhibit a wide range of biological effects. Some of them are powerful free radical scavengers (and so, have antioxidant activity). Depending on the extraction procedure, the antioxidant activity can vary, being in some cases, higher in leaves than in fruits (Rubilar et al. 2011). In the case of the present study, the antioxidant activity recorded in leaves was similar to that observed by Rubilar et al. (2011) in stems. GonzálezVillagra et al. (2018) determined that fully expanded

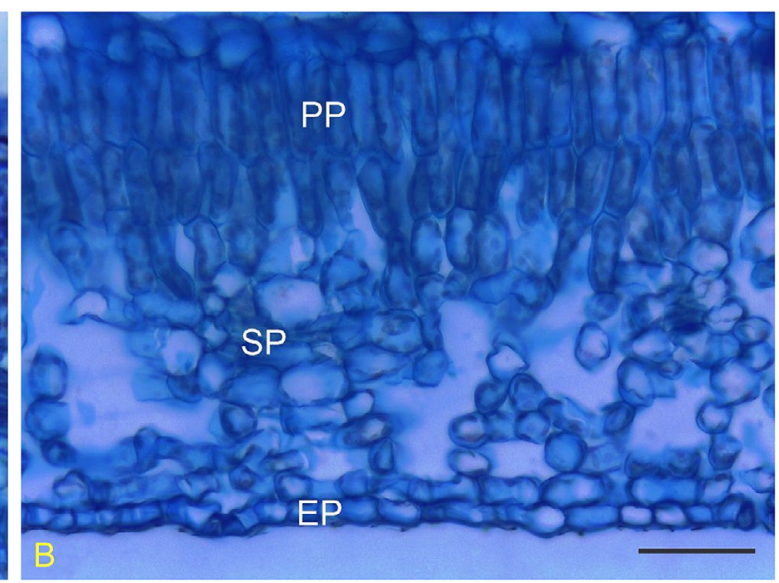
can improve the $\mathrm{CO}_{2}$ diffusion, and facilitate its entry myrtle and Eugenia plants under salinity (Acosta-Motos 
A. chilensis leaves subjected to drought stress, had higher antioxidant activity and higher capacity to synthesize ABA regulating stomatal closure, than young leaves in the same condition. In addition, young leaves showed higher TPC and total anthocyanin levels but lower antioxidant activity in the $10^{\text {th }}$ day of drought stress treatment. The authors suggest that the fully expanded leaves of stressed A. chilensis plants have a strong antioxidant capacity to tolerate drought stress.

The mechanism by which an antioxidant compound interacts with a radical molecule depends on the structural conformation of the antioxidant (Mishra et al. 2012). Granato et al. (2018) indicated that no single antioxidant activity assay will reflect the total antioxidant capacity. Different antioxidant activity methods have particularities depending on mechanisms of action, types of radical, $\mathrm{pH}$, time of exposition and temperature. One of the tests used in this study was the DPPH assay, which is simple due to its stable nitrogen radical, but has problems with many antioxidants by reacting with different kinetics or not reacting at all (Mishra et al. 2012). This assay is also pHdependent, and the final result could be influenced by the deprotonation of the phenolic group (Mishra et al. 2012, Tirzitis and Bartosz 2010). The other method used in this study was the ABTS assay, which consists of an oxidation reaction of the coloured cation $\mathrm{ABTS}^{\bullet+}$. The ABTS assay can be applied to lipophilic and hydrophilic compounds (Huyut et al. 2017). Thus, the results of the current study determined in the DPPH assay, an increase in antioxidant activity in summer in both types of leaves, coinciding with the greater radiation, without the same trend in ABTS assay. Therefore, as indicated by Granato et al. (2018), it is evident that "antioxidant activity" involves complex interactions.

Screening spectrophotometric methods characterizing the samples can also give an idea of total phenolic

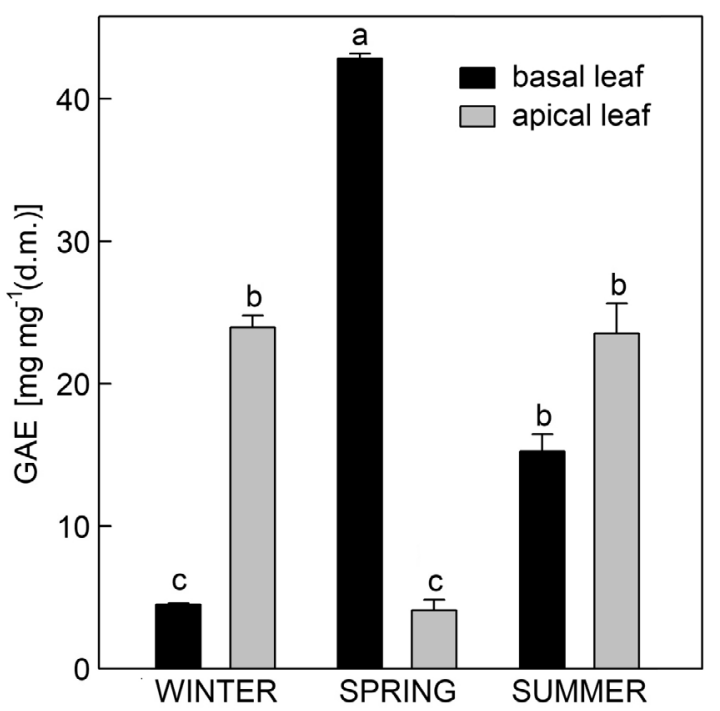

Fig. 2. Total phenolic content (TPC; expressed as GAE) in basal and apical leaves of $A$. chilensis in the different seasons of the year. Means \pm SEs of six samples from each season of the year. Different letters indicate significant differences according to Tukey's test (one-way ANOVA, $P \leq 0.05$ ). content in the matrix. The relationship between TPC and antioxidant activity has been reported in several studies (Rawat et al. 2011). However, Kabra et al. (2019) indicated that in the extracts of Myrica esculenta leaves, the relationship between phenolic compounds and antioxidant activity could be influenced by phytochemical composition of each extract and the use of two different mechanisms of radical scavenging (DPPH and ABTS assays). Similarly, Zhang et al. (2018) indicated in their DPPH and ABTS assays, different values for nineteen citrus genotypes belonging to Citrus reticulata Blanco, in their peels, juice, pulp and seeds. In addition, in this study, it is important to highlight the differences of TPC content and the relation with light in the basal spring leaves. The phenolic content may be influenced by the quantity and quality of this active substance, type of plant habitat, season of the year and conditions in which plants are grown (Stanković et al. 2017). In this context, the light in the spring season could be favourable for the synthesis of these active compounds in $A$. chilensis leaves and their relationship with the increased photosynthesis to leads to an increase in secondary metabolism. In summary, the TPC and antioxidant activity variation between apical and basal $A$. chilensis leaves in the same season might be due to the different phytochemical composition.

As a general conclusion of this study, it was determined that the $A$. chilensis basal leaves showed higher photosynthetic activity as indicated by stable $\mathrm{F}_{\mathrm{v}} / \mathrm{F}_{\mathrm{m}}$ values and also higher TPC under high irradiance. In both types of leaves, the increase in irradiance was accompanied by an increase in NPQ values, reflecting a safe mechanism to dissipate excess radiation energy. In addition, apical leaves display some morphological adaptions, such as the increase in intercellular spaces in order to facilitate the transport of $\mathrm{CO}_{2}$ to the chloroplasts Finally, in order to take advantage of the research, it is necessary to know in the future, the performance of the activities of the different antioxidant enzymes and compare these antioxidants mechanisms in both types of leaves.

\section{References}

Acosta-Motos, J.R., Diaz-Vivancos, P., Álvarez, S., FernándezGarcía, N., Sanchez-Blanco, M.J., Hernández, J.A.: Physiological and biochemical mechanisms of the ornamental Eugenia myrtifolia L. plants for coping with $\mathrm{NaCl}$ stress and recovery. - Planta 242: 829-846, 2015a.

Acosta-Motos, J.R., Diaz-Vivancos, P., Álvarez, S., FernándezGarcía, N., Sánchez-Blanco, M.J., Hernández, J.A.: $\mathrm{NaCl}$-induced physiological and biochemical adaptative mechanisms in the ornamental Myrtus communis L. plants. J. Plant Physiol. 183: 41-51, 2015b.

Agulló, V., García-Viguera, C., Domínguez-Perles, R..: Beverages based on second quality citrus fruits and maqui berry, a source of bioactive (poly)phenols: sorting out urine metabolites upon a longitudinal study vicente. - Nutrients 13: 312, 2021.

Barthélémy, D., Caraglio, Y.: Plant architecture: A dynamic, multilevel and comprehensive approach to plant form, structure and ontogeny. - Ann. Bot. 99: 375-407, 2007. 
Benedetti, S.: Monografía de maqui Aristotelia chilensis (Mol.) Stuntzs (issue August) [Monograph of maqui Aristotelia chilensis (Mol.) Stuntzs (August issue) -Non-wood Forest Products Research Program] - Programa de Investigación de Productos Forestales no Madereros, Instituto Forestal, Chile 2012. [In Span.]

Céspedes, C.L., Pavón, N., Domínguez, M., Alarcón, J., Balbontín, C., Kubo, I., El-Hafidi, M., Ávila, J.G.: The chilean superfruit black-berry Aristotelia chilensis (Elaeocarpaceae), maqui as mediator in inflammation-associated disorders. Food Chem. Toxicol. 108: 438-450, 2017.

Damascos, M.A., Prado, C.H.B.A.: Defoliación en la especie invierno-verde Aristotelia chilensis y su efecto sobre el crecimiento inicial de hojas y ramas [Defoliation in the species winter-green Aristotelia chilensis and the effect on the initial growth of leaves and branches.]. - Bosque 22: 45-50, 2001a. [In Span.]

Damascos, M.A., Prado, C.H.B.A.: Leaf phenology and its associated traits in the wintergreen species Aristotelia chilensis (Mol.) Stuntz (Elaeocarpaceae). - Rev. Chil. Hist. Nat. 74: 805-815, $2001 \mathrm{~b}$.

De Menezes, B.B., Frescura, L.M., Duarte, R., Villetti, M.A., da Rosa, M.B.: A critical examination of the DPPH method: Mistakes and inconsistencies in stoichiometry and IC50 determination by UV-Vis spectroscopy. - Anal. Chim. Acta. 1157: 338398, 2021.

Dos Santos Isaias, R.M., De Oliveira Coelho, D., Da Silva Carneiro, R.G.: Role of Euphalerus ostreoides (Hemiptera: Psylloidea) in manipulating leaflet ontogenesis of Lonchocarpus muehlbergianus (Fabaceae). - Botany 89: 581592, 2011.

Fredes, C., Montenegro, G., Zoffoli, J.P., Gómez, M., Robert, P.: Polyphenol content and antioxidant activity of maqui (Aristotelia chilensis [Molina] Stuntz) during fruit development and maduration in central Chile. - Chilean J. agr. Res. 72: 582-589, 2012.

Fredes, C., Montenegro, G., Zoffoli, J.P., Santander, F., Robert, P.: Comparación de los contenidos de fenoles totales, antocianos totales y la actividad antioxidante de frutos ricos en polifenoles que crecen en Chile [Comparison of total phenol contents, anthocyanins and antioxidant activity of polyphenol-rich fruits grown in polyphenol-rich fruits grown in Chile.] - Cienc. Investig. Agr. 41: 49-59, 2014. [In Span.]

Fredes, C., Osorio, M.J., Parada, J., Robert, P.: Stability and bioaccessibility of anthocyanins from maqui (Aristotelia chilensis [Mol.] Stuntz) juice microparticles.- LWT - Food Sci. Technol. 91: 549-556, 2018.

Fuentealba, J., Dibarrart, A., Saez-Orellana, F., Fuentes-Fuentes, M.C., Oyanedel, C.N., Guzmán, J., Perez, C., Becerra, J., Aguayo, L.G.: Synaptic silencing and plasma membrane dyshomeostasis induced by amyloid- $\beta$ peptide are prevented by Aristotelia chilensis enriched extract. - J. Alzheimer's Dis. 31: 879-889, 2012.

Fuentes, L., Figueroa, C.R., Valdenegro, M., Vinet, R.: Patagonian berries: healthy potential and the path to becoming functional foods. - Foods 8: 289, 2019.

Gonçalves, S., Romano, A.: Inhibitory properties of phenolic compounds against enzymes linked with human diseases. - In: Soto-Hernández M (ed.): Phenolic Compounds - Biological Activity. Pp. 99-118. IntechOpen Book Series. 2017.

González-Villagra, J., Rodrigues-Salvador, A., Nunes-Nesi, A., Cohen, J.D., Reyes-Díaz, M.M.: Age-related mechanism and its relationship with secondary metabolism and abscisic acid in Aristotelia chilensis plants subjected to drought stress. Plant Physiol. Biochem. 124: 136-145, 2018.

Granato, D., Shahidi, F., Wrolstad, R., Kilmartin, P., Melton,
L.D., Hidalgo, F.J., Miyashita, K., Camp, J.V., Alasalvar, C., Ismail, A.B., Elmore, S., Birch, G.G., Charalampopoulos, D., Astley, S.B., Pegg, R., Zhou, P., Finglas, P.: Antioxidant activity, total phenolics and flavonoids contents: should we ban in vitro screening methods?. - Food Chem. 264: 471-475, 2018.

Harnly, J.: Antioxidant methods. - J. Food Compos. Anal. 64: 145-146, 2017.

Hernández, J.A., Escobar, C., Creissen, G., Mullineaux, P.M.: Role of hydrogen peroxide and the redox state of ascorbate in the induction of antioxidant enzymes in pea leaves under excess light stress. - Funct. Plant Biol. 31: 359-368, 2004.

Huyut, Z., Beydemir, Ş., Gülçin, I.: Antioxidant and antiradical properties of selected flavonoids and phenolic compounds. Biochem. Res. Int. 2017: 7616791, 2017.

Kabra, A., Sharma, R., Hano, C., Kabra, R., Martins, N., Baghel, U.S.: Phytochemical composition, antioxidant, and antimicrobial attributes of different solvent extracts from Myrica esculenta Buch.-Ham. ex. D. Don Leaves Atul. Biomolecules 9: 357, 2019.

Kulisic, T., Radonic, A., Katalinic, V., Milos, M.: Use of different methods for testing antioxidative activity of oregano essential oil. - Food Chem. 85: 633-640, 2004.

Kuskoski, E.M., Asuero, A.G., García-Parilla, M.C., Troncoso, A.M., Fett, R.: Actividad antioxidante de pigmentos antociánicos [Antioxidant activity of anthocyanin pigments anthocyanins]. - Ciênc. Tecnol. Aliment. 24: 691-693, 2004. [In Span.]

Lusk, C.H.: Leaf area and growth of juvenile temperate evergreens in low light: species of contrasting shade tolerance change rank during ontogeny. - Funct. Ecol. 18: 820-828 2004.

Masek, A., Latos-Brozio, M., Kałuzna-Czaplinska, J., Rosiak, A., Chrzescijanska, E.: Antioxidant properties of green coffee extract. - Forests 11:557, 2020.

Masoodi, H., Villaño, D., Zafrilla, P.: A comprehensive review on fruit: Aristotelia chilensis (maqui) for modern health: towards a better understanding. - Food Funct. 10: 3057-3067, 2019.

Mathur, S., Jain, L., Jajoo., A.: Photosynthetic efficiency in sun and shade plants. Photosynthetica 56: 354-365, 2018.

Mendoza, C.A., Turrión, M.B., Aceñolaza, P.G., Gallardo, J.F., Pando, V.: Retranslocación de nutrientes en especies dominantes de bosques del espinal Mesopotámico (Argentina) [Nutrient re-translocation in dominant species dominant species in Mesopotamian espinal forests (Argentina)]. Bosque 35: 185-193, 2014. [In Span.]

Mishra, K., Ojha, H., Chaudhury, N.K.: Estimation of antiradical properties of antioxidants using DPPH- assay: a critical review and results. - Food Chem. 130: 1036-1043, 2012.

Molina-Montenegro, M.A., Torres-Díaz, C., Carrasco-Urra, F., González-Silvestre, L.A., Gianoli, E.: Plasticidad fenotípica en dos poblaciones antárticas de Colobanthus quitensis (Caryophyllaceae) bajo un escenario simulado de cambio global [Phenotypic plasticity in two Antarctic populations of Colobanthus quitensis (Caryophyllaceae) under a global modified simulated scene.]. - Gayana Bot. 69: 152-160, 2012. [In Span.]

Mongkolsilp, S., Pongbupakit, I., Sae-Lee, N., Sitthihaworm, W.: Radical scavenging activity and total phenolic content of medicinal plants used in primary health care. - SWU J. Pharm. Sci. 9: 32-35, 2004.

Morales, P., Carvalho, A.M., Sánchez-Mata, M.C., Cámara, M., Molina, M., Ferreira, I.C.F.R.: Tocopherol composition and antioxidant activity of spanish wild vegetables. - Genet. Resour. Crop Evol. 59: 851-863, 2012.

Moreno, G., Vela, P., Alvarez, S., Martha, O.: La fluorescencia de la clorofila $a$ como herramienta en la investigación de efectos 
tóxicos en el aparato fotosintético de plantas y algas [The chlorophyll fluorescence (a) as a tool in the research of toxic effects in photosynthetic machinery of plants and algae.]. Rev. Educ. Bioquím. 27: 119-129, 2008. [In Span.]

Moya, M., González, B., Doll, U., Yuri, J.A., Vogel, H.: Different covers affect growth and development of three maqui clones (Aristotelia chilensis [Molina] Stuntz). - J. Berry Res. 9: 449458, 2019.

Murchie, E.H., Lawson, T.: Chlorophyll fluorescence analysis: a guide to good practice and understanding some new applications. - J. exp. Bot. 64: 3983-3998, 2013.

Naikoo, M.I., Dar, M.I., Raghib, F., Jaleel, H., Ahmad, B., Raina, A., Ahmad Khan, F., Naushin, F.: Role and regulation of plants phenolics in abiotic stress tolerance: an overview. Plant Signal. Mol.: 157-168, 2019.

Ortiz, T., Argüelles-Arias, F., Begines, B., García-Montes, J.M., Pereira, A., Victoriano, M., Vázquez-Román, V., Pérez Bernal, J.L., Callejón, R.M., De-Miguel, M., Alcudia, A.: Native chilean berries preservation and in vitro studies of a polyphenol highly antioxidant extract from maqui as a potential agent against inflammatory diseases. - Antioxidants 10: 843, 2021.

Rawat, S., Jugran, A., Giri, L., Bhatt, I.D., Rawal, R.S.: Assessment of antioxidant properties in fruits of Myrica esculenta: A popular wild edible species in indian himalayan region. - Evidence-based Complement. Altern. Med. 2011: 512787, 2011.

Repetto-Giavelli, F., Cavieres, L.A., Simonetti, J.A.: Respuestas foliares de Aristotelia chilensis (Molina) stuntz (Elaeocarpaceae) a la fragmentación del bosque maulino [Foliar responses of Aristotelia chilensis (Molina) stuntz (Elaeocarpaceae) to maulin forest fragmentation]. - Rev. Chilean Hist. Nat. 80: 469-477, 2007. [In Span.]

Rubilar, M., Jara, C., Poo, Y., Acevedo, F., Gutierrez, C., Sineiro, J., Shene, C.: Extracts of maqui (Aristotelia chilensis) and murta (Ugni molinae Turcz.): sources of antioxidant compounds and $\alpha$-glucosidase $/ \alpha$-amylase inhibitors. - J. Agr. Food Chem. 59: 1630-1637, 2011.

Sáez, P.L., Bravo, L.A., Sáez, K.L., Sánchez-Olate, M., Latsague, M.I., Ríos, D.G.: Photosynthetic and leaf anatomical characteristics of Castanea sativa: a comparison between in vitro and nursery plants. - Biol. Plant. 56: 15-24, 2012.

Salinas, J., Cabellé, G.: Maqui, el fruto silvestre de mayor importancia en Chile. - Instituto Forestal, Chile. 248, 2020.

Scossa, F., Fernie, A.R.: The evolution of metabolism: how to test evolutionary hypotheses at the genomic level. - Comput. Struct. Biotechnol. J. 18: 482-500, 2020.

Sembiring, E.N., Elya, B., Sauriasari, R.: Phytochemical screening, total flavonoid and total phenolic content and antioxidant activity of different parts of Caesalpinia bonduc (L.) Roxb. - Pharmacogn. J. 10: 123-127, 2018.

Stanković, M., Ćurčić, S., Zlatić, N., Bojović, B.: Ecological variability of the phenolic compounds of Olea europaea L. leaves from natural habitats and cultivated conditions. Biotechnol. Biotechnol. Equip. 31: 499-504, 2017.

Tirzitis, G., Bartosz, G.: Determination of antiradical and antioxidant activity: basic principles and new insights. - Acta biochim. polon. 57: 139-142, 2010.

Turchetti, G., Paz, C. : Aristotelia chilensis (Mol.) Stuntz: a natural source of bioactive compounds. - Curr. traditional. Med. 5: 66-74, 2019.

Vidal, J.L., Avello, L.M., Loyola, C.C., Campos, P.J., Aqueveque, M.P., Dungan, R.S., Galotto, L.M., Guarda, M.A.: Microencapsulation of maqui (Aristotelia chilensis [Molina] Stuntz) leaf extracts to preserve and control antioxidant propertie. - Chilean J. agr. Res. 73: 17-23, 2013.

Yang, Y.J., Zhang, S.B., Wang, J.H., Huang, W.: The decline in photosynthetic rate upon transfer from high to low light is linked to the slow kinetics of chloroplast ATP synthase in Bletilla striata. - Photosynth. Res. 144: 13-21, 2020.

Zhang, H., Yang, Y.F., Zhou, Z.Q.: Phenolic and flavonoid contents of mandarin (Citrus reticulata Blanco) fruit tissues and their antioxidant capacity as evaluated by DPPH and ABTS methods. - J. Integr. Agric. 17: 256-263, 2018.

Zhen, S., Bugbee, B.: Far-red photons have equivalent efficiency to traditional photosynthetic photons: implications for redefining photosynthetically active radiation. - Plant Cell Environ. 43: 1259-1272, 2020.

Zúñiga, G.E., Tapia, A., Arenas, A., Contreras, R.A., ZúñigaLibano, G.: Phytochemistry and biological properties of Aristotelia chilensis a chilean blackberry: a review. Phytochem. Rev. 16: 1081-1094, 2017. 